\title{
Development of a New Departure Aversion Standard for Light Aircraft
}

\author{
Nicholas K. Borer ${ }^{1}$ \\ NASA Langley Research Center, Hampton, Virginia 23681
}

\begin{abstract}
The Federal Aviation Administration (FAA) and European Aviation Safety Agency (EASA) have recently established new light aircraft certification rules that introduce significant changes to the current regulations. The changes include moving from prescriptive design requirements to performance-based standards, transferring many of the acceptable means of compliance out of the rules and into consensus standards. In addition, the FAA/EASA rules change the performance requirements associated with some of the more salient safety issues regarding light aircraft. One significant change is the elimination of spin recovery demonstration. The new rules now call for enhanced stall warning and aircraft handling characteristics that demonstrate resistance to inadvertent departure from controlled flight. The means of compliance with these changes in a safe, cost-effective manner is a challenging problem. This paper discusses existing approaches to reducing the likelihood of departure from controlled flight and introduces a new approach, dubbed Departure Aversion, which allows applicants to tailor the amount of departure resistance, stall warning, and enhanced safety equipment to meet the new proposed rules. The Departure Aversion approach gives applicants the freedom to select the most cost-effective portfolio for their design, while meeting the safety intent of the new rules, by ensuring that any combination of the selected approaches will be at a higher equivalent level of safety than today's status quo.
\end{abstract}

\section{Introduction}

In March of 2016, the Federal Aviation Administration (FAA) issued a Notice of Proposed Rulemaking (NPRM) to revise Title 14 of the Code of Federal Regulations (CFR), including Part 23, which contains the airworthiness standards for normal, utility, acrobatic, and commuter category airplanes (with no more than 19 passengers and a takeoff weight of less than 19,000 pounds). ${ }^{1}$ Similarly, and in the spirit of harmonization of regulations between Europe and the United States, the European Aviation Safety Agency (EASA) released a Notice of Proposed Amendment (NPA) to Certification Specification 23 (CS-23) on 23 June 2016. ${ }^{2}$ These proposals have been adopted in 14 CFR Part 23 Amendment 64 and CS-23 Amendment 5, both of which will be implemented in August 2017. The NPRM and NPA proposed significant changes from the current Part 23/CS-23 rule language, in an effort to move from what were viewed as prescriptive design requirements to performance-based airworthiness standards. This change was designed to maintain the equivalent level of safety of the current Part 23/CS-23 fleet, with enhancements to perceived high-risk areas not sufficiently addressed by current rules, namely: certification for flight into icing conditions, enhanced stall characteristics, and minimum control speeds for multiengine aircraft. The change to performance-based standards was seen as a way to encourage adoption of new, safety-enhancing technologies that were slow to be adopted to Part 23/CS-23 due to the lengthy rulemaking process. The use of consensus standards as a means of compliance is encouraged by the NPRM and NPA (and the activities that led to the NPRM/NPA). In response, ASTM International formed Committee F44 on General Aviation ${ }^{3}$ to develop standards that could be an acceptable means of compliance to the proposed new rules in Part 23/CS-23.

\section{A. Changes to Low-Speed Flight Characteristics Rules}

The Part 23 NPRM preamble includes "enhanced stall characteristics" as a targeted area for safety improvement. This is in response to a number of studies, including data gathered from the Aircraft Owners and Pilot's Association Air Safety Foundation ${ }^{4}$ and the Joint General Aviation Steering Committee, ${ }^{5}$ which found that Loss of Control (LOC) is one of the leading causes of fatal accidents for light aircraft. The NPRM ${ }^{1}$ states:

\footnotetext{
${ }^{1}$ Aerospace Engineer, Aeronautics Systems Analysis Branch, MS 442, AIAA Senior Member.
} 
The proposed requirements would also include new enhanced standards for resistance to departure from controlled flight. Recognizing that the largest number of fatal accidents for part 23 airplanes results from LOC in flight, the FAA proposes to update certification standards to address these risks. LOC happens when an airplane enters a flight regime outside its normal flight envelope or performance capabilities and develops into a stall or spin, an event that can surprise the pilot. A pilot's lack of awareness of the state of the airplane in flight and the airplane's low-speed handling characteristics are the main causal factors of LOC accidents. Furthermore, stall and departure accidents are generally fatal because an airplane is often too low to the ground for the pilot to recover. Improving safety that reduces stall and LOC accidents would save lives. The FAA is therefore proposing new rules for stall characteristics and stall warnings that would result in airplane designs more resistant to inadvertently departing controlled flight.

Previously, aircraft certified under Part 23 could depart controlled flight in the form of a spin, if the aircraft exhibited acceptable recovery characteristics. The FAA indicates that it no longer believes the design of spincapable (but recoverable) aircraft is prudent for aircraft other than those approved for aerobatics. Per the NPRM ${ }^{1}$ :

The FAA also proposes new requirements in $\$ 23.215^{*}$ for airplane stall characteristics and stall warning that would result in airplane designs more resistant to inadvertently stalling and departing controlled flight. These proposed requirements would increase the level of safety over the current requirements. At the same time, the FAA proposes to eliminate the spin recovery requirement in the current rules for normal category airplanes. The FAA believes the spin recovery requirement is unnecessary for normal category airplanes because the vast majority of inadvertent stalls leading to spin entry occur below a safe altitude for spin recovery. However, airplanes certificated for aerobatics would still have to meet spin recovery requirements.

In the final bid to improve low-speed flight characteristics (and reduce the onset of LOC accidents), the FAA proposes enhanced awareness mechanisms when the aircraft is close to stall. The NPRM ${ }^{1}$ states:

The FAA also proposes to address pilot stall awareness by requiring warnings that are more effective and by allowing new approaches to improve pilot awareness of stall margins. These warnings could be as simple as angle of attack or energy awareness presentations, or sophisticated envelope protection systems that add a forward force to the pilot's controls as the airplane speed and attitude approach stall.

Overall, the NPRM consolidates the current regulations of $\S 23.201$ and $\S 23.203$ (stall characteristics), §23.207 (stall warning), and $\$ 23.221$ (spins). The 14 CFR Part 23 Amendment 64 rule language drops many of the prescriptive methods and means of compliance and focuses on functional performance characteristics. The corresponding new rule, implemented as $\$ 23.2150$, reads as follows ${ }^{6}$ :

$\S 23.2150$ Stall characteristics, stall warning, and spins.

(a) The airplane must have controllable stall characteristics in straight flight, turning flight, and accelerated turning flight with a clear and distinctive stall warning that provides sufficient margin to prevent inadvertent stalling.

(b) Single-engine airplanes, not certified for aerobatics, must not have a tendency to inadvertently depart controlled flight.

(c) Levels 1 and 2 multiengine airplanes, not certified for aerobatics, must not have a tendency to inadvertently depart controlled flight from thrust asymmetry after a critical loss of thrust.

(d) Airplanes certified for aerobatics must have controllable stall characteristics and the ability to recover within one and one-half additional turns after initiation of the first control action from any point in a spin, not exceeding six turns or any greater number of turns for which certification is requested, while remaining within the operating limitations of the airplane.

(e) Spin characteristics in airplanes certified for aerobatics must not result in unrecoverable spins-

(1) With any use of the flight or engine power controls; or

(2) Due to pilot disorientation or incapacitation.

The term "Level," as noted in $\$ 23.2150(\mathrm{c})$, refers to the number of passenger seats onboard the aircraft. ${ }^{6}$ In the move towards performance-based standards, the FAA acknowledged that the majority of the risk involved with an aircraft involves the passengers onboard the aircraft, with a minimal risk to those not on the aircraft. Hence, "Level" (commensurate with "risk level") is correlated with number of passenger seats. Specifically, \$23.2005 drops all but the normal category for aircraft, and gives the following "certification levels" associated with the normal category:

- Level 1 - maximum seating configuration of 0-1 passengers,

- Level 2 - maximum seating configuration of 2-6 passengers,

- Level 3 - maximum seating configuration of 7-9 passengers, and

- Level 4 - maximum seating configuration of 10-19 passengers.

* The FAA has renumbered this section to $\$ 23.2150$ in the final rule. 
The CS-23 Amendment 5 rule largely mirrors the 14 CFR Part 23 Amendment 64 rule, as a means to achieve harmonization for light aircraft certification standards between the FAA and EASA. EASA's rule for low-speed flight characteristics ${ }^{7}$ states:

CS 23.2150 Stall characteristics, stall warning, and spins

(a) The aeroplane must have controllable stall characteristics in straight flight, turning flight, and accelerated turning flight with a clear and distinctive stall warning that provides sufficient margin to prevent inadvertent stalling. A stall warning that is mutable for aerobatic flight phases is acceptable.

(b) Single-engine aeroplanes, not certified for aerobatics, must not have a tendency to hazardously depart controlled flight inadvertently.

(c) Level-1 and -2 multi-engine aeroplanes, not certified for aerobatics, must not have a tendency to hazardously depart controlled flight inadvertently from thrust asymmetry after a critical loss of thrust.

(d) Aeroplanes certified for aerobatics must have controllable stall characteristics and the ability to recover within one and one-half additional turns after initiation of the first control action from any point in a spin, not exceeding six turns or any greater number of turns for which certification is requested, while remaining within the operating limitations of the aeroplane.

(e) Aeroplanes intended for aerobatics have the ability to recover from any manoeuvre, without exceeding limitations or exhibiting unsafe characteristics

One difference is noted between the FAA's proposed \$23.2150(b) and EASA's proposed CS-23.2150(b). The FAA rule only states that inadvertent departure from controlled flight must be avoided, whereas EASA adds the modifier "hazardously" to the departure. It is unclear if this will stay in the final rule released in August, but this appears to allow for some degree of allowable departure behavior that is not explicitly called out in the FAA rule.

\section{B. Development of Consensus Standards}

The use of consensus standards as a means of compliance to performance-based rules was considered acceptable to the FAA and EASA for Light Sport Aircraft (LSA), ${ }^{8,9}$ a particular class of small, simple aircraft with deliberately limited capabilities. The means of compliance for LSA airworthiness reside within standards developed by ASTM International Committee F37 on Light Sport Aircraft, ${ }^{10,11}$ a consensus standard organization that includes producers, users, and general interest members (including regulators). The experience gained with the LSA structure was used to inform changes made to the Part 23/CS-23 structure. The shift towards consensus standards resulted in a dramatic reduction in the size of the rule language as compared to the existing rules. However, the prescriptive design requirements were not omitted; rather, they have been transferred into consensus standards. These standards can be maintained, modified, updated, and improved through a consensus process that includes input from producers, users, other general interest members, and regulators. ASTM International formed Committee F44 on General Aviation ${ }^{3}$ to maintain these consensus standards, which will be considered one (but not necessarily the only) means of compliance to the performance-based rules.

The initial role of ASTM F44 was to identify the prescriptive design portions within the existing Part 23/CS-23 rules and incorporate that information into standards under the jurisdiction of F44. Some cleanup was necessary, including harmonizing differences between Part 23 and CS-23 and addressing some known inconsistencies and outdated information that had not been dealt with in rulemaking. The committee released a full set of initial standards, complete with the former Part 23/CS-23 design guidance that had been stripped out of the rules, to coincide with the release of the NPRM. Unfortunately, there is little guidance or equivalency in the old rules with respect to what it means to "not have a tendency to depart controlled flight." With the elimination of departure recovery in the new rules (largely through elimination of the one- and three-turn spin recovery requirements for Normal and Utility category aircraft), ASTM F44 needs to develop a means of compliance with respect to a departure-resistant aircraft instead of a departure-recoverable aircraft.

Currently, the standard that is used as a means of compliance for the requirements of $\$ 23.2150 / \mathrm{CS}-23.2150$ is F3180/F3180M-16, Standard Specification for Low-Speed Flight Characteristics of Aeroplanes. ${ }^{12}$ In the initial release of this standard, the committee incorporated what little acceptable guidance existed to date with respect to departure-resistant aircraft (namely, those that were not required to demonstrate recovery from spins). Now, the committee is moving forward to merge past guidance, flight research, and advances in modern technology to develop a standard that results in aircraft that are less likely to depart controlled flight. This Departure Aversion approach will allow an applicant to show compliance with the proposed §23.2150/CS-23.2150 via a portfolio of methods, which includes aerodynamic means, systems solutions, enhanced pilot engagement, and combinations thereof. This paper will summarize past guidance for departure resistance and corresponding flight research regarding loss of control, and will present the committee's latest framework for Departure Aversion. 


\section{Existing Departure-Related Guidance}

Avoiding inadvertent departure from controlled flight has been a vexing issue associated with light aircraft from the dawn of aviation to the present. Prior to a previous major overhaul of Part 23 guidance in the 1980s, a number of different studies were conducted with respect to stall/spin accidents. The National Transportation Safety Board (NTSB) made several recommendations in a 1972 study of stall/spin accidents, including changes to training, research into new warning systems and aircraft departure characteristics, and overall awareness and outreach to the pilot community. ${ }^{13}$ A 1977 study by Ellis ${ }^{14}$ suggested improvements to stall warning systems, aerodynamic features and control force limits to change stall behavior, and limiting control force changes due to configuration changes as ways to reduce the stall-related accident rate. Ontiveros conducted a limited study of different stall warning devices, which found that enhanced stall warning systems (especially tactile feedback) were far more effective at alerting an otherwise distracted pilot than the standard aural systems ${ }^{15}$. The National Aeronautics and Space Administration (NASA) investigated the departure characteristics of light aircraft using wind tunnels, subscale aircraft, and fullscale aircraft. NASA used the results of these investigations to develop aerodynamic features and design rules that would cause the aircraft to resist spins in pro-spin situations. ${ }^{16}$

\section{A. Regulations}

Certification paths do exist that allow other than spin-recoverable aircraft. The FAA's 14 CFR Part 23 Amendment $62,{ }^{17} \S 23.221$ (a)(2) allows an applicant to show that an airplane is spin resistant. This is accomplished through a series of "abused stalls," which are similar to the wings-level, turning, and accelerated stall maneuvers in $\$ 23.201$ and $\$ 23.203$, but with the directional control (rudder) positioned such that the stalls are entered in an uncoordinated fashion (e.g., with sideslip). Additionally, §23.221(a)(2)(ii) includes a number of "sustained control abuse" maneuvers, designed to illustrate the tendency (or lack thereof) for the aircraft to depart controlled flight when pro-spin controls are held for a period of time. The creation of these criteria involved a decades-long cooperative research, technology development, and testing effort that included the FAA, NASA, and the General Aviation Manufacturer's Association (GAMA) ${ }^{16,18}$ In practice, few aircraft have been designed or certified that can meet all of the requirements of this standard. A recent example of an aircraft that is capable of meeting these requirements is ICON Aircraft's A $5^{19}$, though that particular aircraft is not certified under Part 23.

EASA's Certification Specifications for Very Light Aeroplanes (CS-VLA) ${ }^{20}$ includes a provision under CSVLA-221(b) that allows an applicant to show a design is "characteristically incapable of spinning" in lieu of conducting spin tests. In this case, the applicant conducts the specified low-speed flight maneuvers at conditions with margin over those for which approval is being sought, including flight tests at a higher gross weight, a center of gravity aft of the rearmost position, and with reduced elevator and rudder travel vs. what will be approved on the design. These criteria are identical to older versions of the FAA's Part 23, namely, §23.221(d), which was removed with the adoption of Amendment 50 of the regulation. ${ }^{21}$

\section{B. Consensus Standards}

ASTM Standard F3180/F3180M-16 ${ }^{12}$ contains language meant to comply with the proposed rules in $\$ 23.2150$ of the FAA rule and CS-23.2150 of the EASA rule. However, the first release of this standard only incorporated existing means of compliance, with some small changes. Namely, with respect to the clause in $\$ 23.2150$ (b)/CS23.2150 (b) regarding the significant change in what were formerly spin recovery characteristics, F3180/F3180M presents the two existing departure-resistance criteria currently available in the rules: "Alternative 1," which is the spin resistance criteria formerly in $\$ 23.221(\mathrm{a})(2)$, and "Alternative 3," which is the "characteristically incapable of spinning" criteria for a subset of airplanes similar to VLA, adapted from CS-VLA-221(b). In recognition of upcoming revisions to the standards, F44 also introduced "Alternative 2" into the standard language, which simply states that the applicant may propose a combination of aerodynamic and systems-based protections deemed acceptable by the local civil airworthiness authority as a means of compliance for showing resistance to departure.

Additionally, ASTM Standard F3180/F3180M-16 captures means of compliance related to stalls and stall warning, currently codified in $\$ 23.201, \S 23.203$, and $\$ 23.207$ of Part 23 Amendment 62 (and similarly for CS-23 Amendment 3). The maneuvers specified in $\$ 23.201$ and $\$ 23.203$ remain largely unchanged; however, the warning requirements in $\$ 23.207$ have been updated per the NPRM and NPA's request for enhanced stall warning as part of the effort to reduce LOC-related accidents. In particular, for most aircraft, the ASTM standard currently requires either a combination of tactile ("stick shaker") and aural stall warnings, or a progressive series of two aural annunciations related to low-speed awareness followed by the stall warning. 


\section{Concepts to Mitigate Accidents Due to Inflight Loss of Control}

Since the creation of ASTM Standard F3180/F3180M-16 and the subsequent publication of the NPRM and NPA, comments have been received from the aviation community that the current departure and stall warning approaches discussed within the ASTM standard are not adequate. Committee F44 indicated its awareness of this issue by putting in the "placeholder" mentioned above, that is, "Alternative 2." The rationale for Alternative 2 is simple: in the decades the two current departure-resistance rules have been in existence (codified as "Alternative 1" and "Alternative 3" in F3180/F3180M-16), few aircraft have been designed, much less certified or enjoyed commercial success, that fully meet either of these criteria. Several commercially successful designs have been created that partially meet these requirements, but these designs have required additional scrutiny through the Equivalent Level of Safety (ELOS) process to receive exception from the spin recovery requirements in the existing \$23.221. Two examples of recent aircraft that use enhanced departure resistance approaches include Columbia Aircraft Corporation's (now Textron Aviation) LC40-550FG ${ }^{22}$ and Cirrus Design Corporation's SR20. ${ }^{23}$

The challenge, and strength, of consensus standards is that they must balance the needs of the diverse stakeholders within the committee, which, done properly, reflect a fair makeup of the community at large. Regarding loss of control and proposed means of compliance to the new $\$ 23.2150$ rule, the consensus standard committee must balance issues such as safety goals, cost of compliance, ease of implementation, and reduction of ancillary consequences. The stated goal of the overall Part 23 rewrite has often been summarized as "twice the safety at half the cost," though the challenges associated with LOC reduction tend to focus more on the increase in safety, with the cost reduction coming from simplification of prescriptive requirements in other areas not directly related to LOC. To successfully achieve this balance amongst the stakeholders, ASTM Committee F44 has held a number of internal meetings, as well as two Loss of Control workshops in conjunction with some of its face-to-face committee meetings, to solicit ideas, approaches, and issues associated with reduction of LOC accidents and creation of suitable standards.

\section{A. Layered Defenses}

One outcome of the Loss of Control workshops was that there is no single "silver bullet" to address LOC accidents. Despite the decades of efforts and changes in regulations related to design and training associated with LOC, the recurrence of accidents related to stalls and spins remains strikingly persistent: the same factors addressed in $1977^{14}$ continue to show up in today's accidents, ${ }^{5}$ with the latter report showing LOC as the leading cause of fatal accidents (over $40 \%$ of all fatal accidents during the reporting period). Accident data from $2013^{4}$ indicates that pilotrelated errors in non-commercial, fixed-wing general aviation operations (the type of aircraft largely covered by Part 23) are a factor in $72.9 \%$ of fatal accidents. Assuming that LOC trends similarly with pilot error vs. other causes, and considering that "other or unknown" accounts for $18.1 \%$ of fatal accidents in this category of aviation, one can deduce that mechanical failures account for a very small subset of total aviation accidents. A familiar refrain at the workshops was the fact that design standards may only impact a small fraction of the accidents associated with loss of control, given that the ASTM Committee's scope is limited to the aircraft and does not include the pilot. A persistent question remained: is the "silver bullet" really in the aircraft design, or does it lie with training?

James Reason's article on human error modeling and management places more emphasis on the system in which the humans operate, rather than the unsafe actions of an individual. ${ }^{24} \mathrm{He}$ states that targeting reduction in unsafe acts directly tends to overlook two common features. First, he states that it is "often the best people who make the worst mistakes - error is not the monopoly of an unfortunate few." The 2013 Nall data ${ }^{4}$ may be representative here: although the number of fatal accidents in commercial fixed-wing aviation is substantially less than for noncommercial aviation, the relative percentage of pilot-related causal factors for commercial and non-commercial remains similar, despite regulations that require more experience and greater demonstrated skill for commercial pilots. Second, Reason states, "far from being random, mishaps tend to fall into recurrent patterns. The same set of circumstances can provoke similar errors, regardless of the people involved." This narrative fits well with the observed record of LOC accidents - despite decades of study with accompanying improvements in training and technology, the same types of accidents are occurring in the same phases of flight. Reason concludes his observations of these overlooked features by stating, "The pursuit of greater safety is seriously impeded by an approach that does not seek out and remove the error provoking properties within the system at large."

Reason's "Swiss Cheese Model" of system accidents reflects the different types of failures and the roles of multiple defenses against such failures. Each "slice" of cheese has holes that represent either active failures - unsafe acts committed by people directly in contact with the system, or latent conditions - situations which arise from decisions made by designers, builders, procedure writers, and top-level management. ${ }^{24}$ The number of slices represents the number of defenses against a particular hazard, and the holes in the slices represent omissions in a 
particular defense - either due to active failures or latent conditions. If the slices are arranged such that any set of "holes" line up, an "error trajectory" is available that can lead from a hazard to an accident. One adaptation of this model is shown in Figure 1.

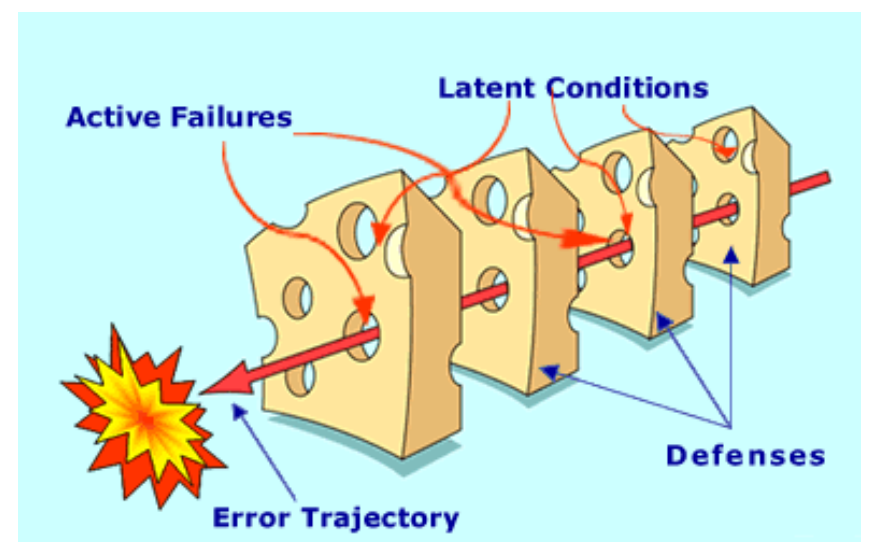

Figure 1. Adaptation of Reason's "Swiss Cheese Model" of human behavior. ${ }^{25}$

Reason $^{24}$ cites trends in human factors research regarding management of unsafe acts; namely, that this can be accomplished by limiting the incidence of dangerous errors, and, "since this will never be wholly effective," developing systems that can be tolerant of errors. The latter approach is similar to the concept of fault-tolerance that is embraced by developers of high reliability systems, such as modern human-rated spacecraft architectures. ${ }^{26}$ Here, the presence of a single (or multiple) independent faults is assumed, and the system is designed to be able to contain these faults and either maintain acceptable performance to continue the mission, or gracefully degrade in such a way as to allow for safe return of the crew. Fault containment is achieved by building in multiple defenses ("slices of cheese") and designing the system such that latent conditions ("holes in the cheese") do not line up with each other. Hence, in a fault-tolerant design with enough defenses, any new active failure (single "new hole" poked in any slice of cheese) cannot propagate through the system.

\section{B. Portfolio Approach to Reducing Inflight Loss of Control}

The concept of a layered defense, along with the lack of a single, manageable casual factor, pointed towards an approach that enables a portfolio of solutions to solve the LOC problem - allowing an applicant to decrease the probability of an LOC-induced accident through a multifaceted, layered application of various techniques. This is analogous to the approach used to design for aircraft survivability, where total probability of loss is a combination of susceptibility (e.g., being detected, or being hit if detected) and vulnerability (e.g., the damage inflicted by being hit results in a loss of the aircraft). ${ }^{27}$ Different military aircraft use various combinations of approaches (stealth, maneuverability, robustness) that result in a reduced probability of loss.

Similarly, mitigation of LOC events can be considered as a reduction of probability in several key areas. The FAA and EASA indicated some areas where improvement must be made in the preamble to the NPRM and NPA. These documents focus on ways to increase pilot awareness regarding current aircraft performance state and margins above stall, as well as encouraging new approaches for stall warning, which can be thought of as a reduction in susceptibility to LOC. They also push for designs that do not depart controlled flight as readily as today's aircraft in situations where a distracted pilot may ignore these warnings. Such an approach can be thought of a reduction in vulnerability, since the vehicle is already in a situation where current designs will depart controlled flight. It is further interesting that the FAA and EASA note that the current approach to reduce vulnerability to departure namely, the ability to recover from a spin - is not effective since most of the fatal accidents occur at altitudes that do not allow for sufficient recovery. Though the FAA and EASA drop the requirement for recovery entirely from the rule, this indicates a willingness to accept a departure if recovery could be made in such a way as to be more effective in the low-altitude, high-workload situations where LOC accidents are so prevalent today. The regulators do not necessarily imply that recovery is unimportant - rather, they state that current methods stipulated by the regulations for recovery are insufficient. 


\section{Departure Aversion}

To build upon the portfolio-based concept for mitigation of loss of control, the committee developed a new approach that could score a variety of layered, disparate defenses against LOC. This approach is dubbed Departure Aversion, which is defined as "the holistic tendency of the aircraft to resist unintentional departure from controlled flight." It permits varying degrees of increased departure resistance (through aerodynamics and control limitations), enhanced stall warning, and other safety-enhancing devices (including new indications, displays, and recovery systems). To accomplish this, each approach is reduced to a common currency - "points" - and although different paths each have different individual scores, the aggregate score must meet a minimum threshold. In effect, Departure Aversion is a generic ELOS process for different LOC mitigation paths, which is built from three essential elements: Stall Warning, Departure Resistance, and Safety-Enhancing Equipment.

The total number of Departure Aversion "points" to require depends on the type of aircraft. The new $\$ 23.2150$ rule (language appears earlier in this document) defines different requirements for single vs. multiengine aircraft, airworthiness level, approved vs. not approved for aerobatics, or combinations thereof, as follows:

- All aircraft must comply with $\$ 23.2150(a)$, which requires controllable stall characteristics and specifies an enhanced stall warning as compared to the previous rule.

- All single engine aircraft not certified for aerobatics must meet $\$ 23.2150(b)$, which requires the aircraft to not have a tendency to inadvertently depart controlled flight. This clause also eliminates the need to demonstrate spin recovery, a key component of the previous rule.

- All Level 1 and 2 multiengine aircraft not certified for aerobatics must meet $\$ 23.2150(\mathrm{c})$, which requires the aircraft to not have a have a tendency to inadvertently depart controlled flight after a "critical loss of thrust." This is a new requirement largely affecting light twin engine aircraft that experience rollover accidents at low speed after an engine failure.

- All aircraft certified for aerobatics must meet $\$ 23.2150(\mathrm{~d})$ and $\$ 23.2150(\mathrm{e})$, which define spin and spin recovery characteristics largely similar to previous rules.

A notional flowchart, shown in Figure 2, gives the decision tree for determination of the Departure Aversion score, $S_{D A}$, required in response to these distinctions. The Departure Aversion score is found from the sum of the Stall Warning score, the Departure Resistance Score (if applicable), and the Safety-Enhancing Features score (if applicable). As will become apparent in the next few subsections, the point values associated with various options and maneuvers are set up to ensure that the overall safety of all aircraft is improved with respect to departure from controlled flight, a stipulated goal for the NPRM and NPA.

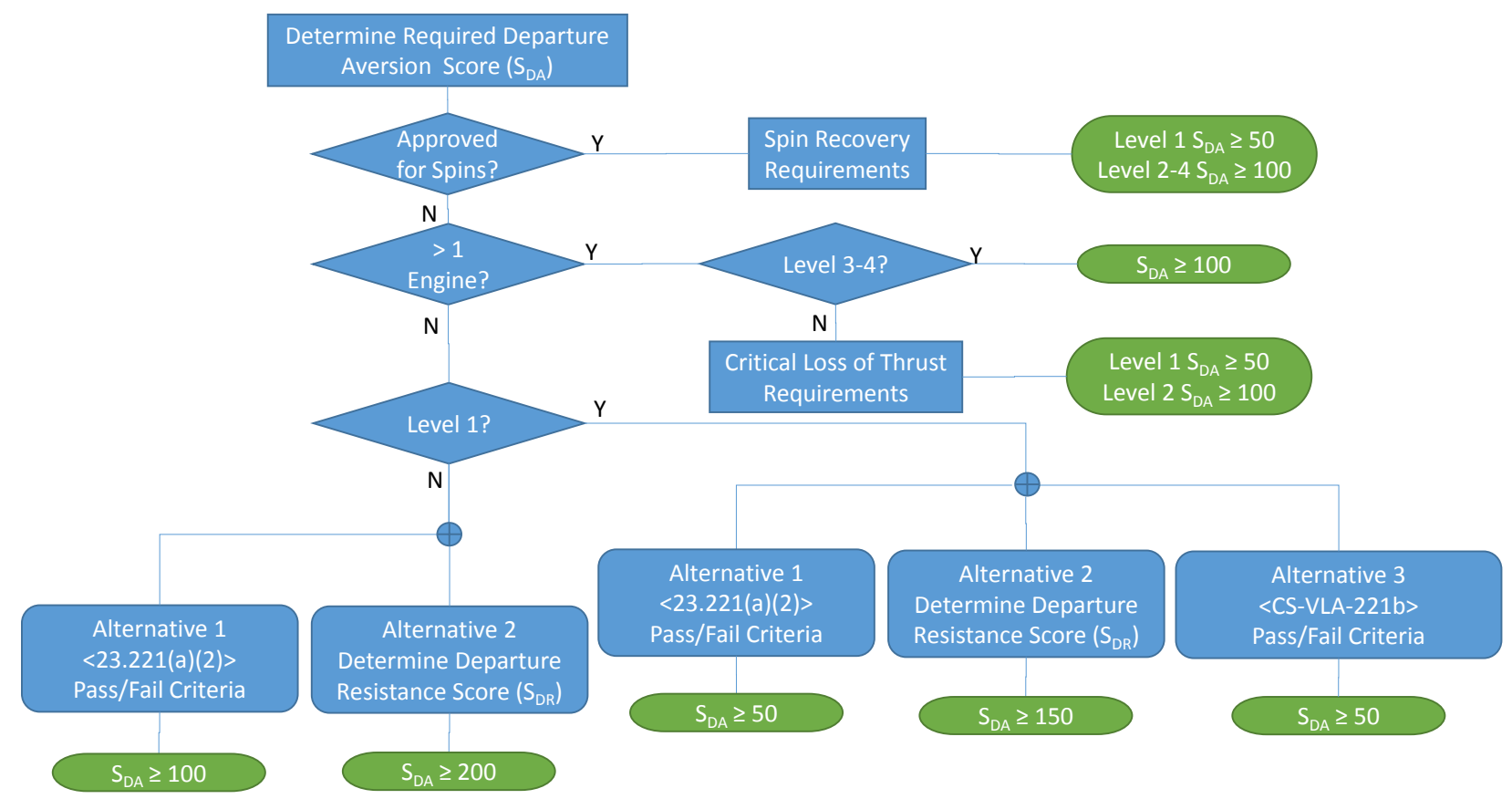

Figure 2. Notional Departure Aversion Score $\left(S_{D A}\right)$ requirements tree. 


\section{A. Stall Warning}

Stall warning systems, and associated requirements, have not changed much in the past few decades. The past stall warning regulations were dictated by $\$ 23.207$, which, besides mandating that the warning be "clear and distinctive," stated that it may be furnished through a system or the "inherent aerodynamic qualities of the airplane." Other than a prohibition on visual devices that "requires the attention of the crew within the cockpit," \$23.207 otherwise just provides activation criteria.

\section{Stall Warning Systems}

As noted earlier in this paper, the FAA and EASA specifically emphasized improved stall warning for LOC reduction. Existing stall warning requirements have typically been met through a single aural tone. This tone is often activated by a change in suction at the leading edge of the wing, which either changes the position of a switch that actuates an electrically-generated sound, or passes air through a pneumatic tube with a calibrated reed.

The effectiveness of a single aural tone, or multiple aural warnings in general, is a subject of much debate. However, direct measurement of the effectiveness of different stall warning systems is more sparse. Ontiveros' 1969 study ${ }^{15}$ investigated the response of five subjects to four different types of stall warning systems: the classic continual-tone stall warning horn, an interrupted horn, a tactile "stick shaker," and a "stick shaker" with an integrated interrupted aural tone ("clacker") type signal. The experiment introduced response to stall warning as secondary to the subjects' primary task in order to evaluate the subjects' response in a high-workload environment. The results indicated that the standard stall warning horn was effective $64 \%$ of the time on average, whereas the interrupted tone was effective $84 \%$ of the time. The tactile "stick shaker" warnings were the most effective; averaging $99 \%$ effectiveness for the shaker-only system, and effectively $100 \%$ for the shaker-clacker arrangement.

At the time of this publication, ASTM International's Low-Speed Flight Characteristics Standard $(\mathrm{F} 3180 / \mathrm{F} 3180 \mathrm{M}-16)^{12}$ focuses on a few, prescriptive alternatives for stall warning, all of which represent an enhancement from today's requirements. In the future, the committee is moving towards a scoring system that assigns point values to different types of warnings. This includes multiple different types of warnings along several different sensory paths. A partial listing of candidate stall warning options is listed in Table 1.

Table 1. Partial Listing of Stall Warning Options

\begin{tabular}{|ll}
\hline Sensory Path & Description \\
\hline Aural & Constant tone \\
\hline Aural & Interrupted tone \\
\hline Aural & Synthetic voice \\
\hline Tactile & Seat vibration \\
Tactile & Yoke or stick vibration \\
\hline Visual & Visual indication independent of pilot focus \\
\hline Visual & Visual indication in primary field of view \\
\hline
\end{tabular}

\section{Scoring}

As evident in the Ontiveros data, today's classic "horn" system does provide warning for some events, but it is not wholly effective. The FAA and EASA goal to "double the safety" can be apportioned to LOC mitigation by attempting to double the effectiveness of the status quo in the targeted areas of improvement. Hence, a stall warning system that is similar to those installed in today's aircraft could be considered about half as good as a "perfect" system, noting that even a "perfect" system is only effective at warning the pilot of the impending stall - it does not actually recover the aircraft. If 100 points is defined as the maximum for the Stall Warning score, $S_{S W}$, a traditional single horn-type aural system would be worth 50 points. This helps to anchor the other values assigned for the different approaches.

One challenge associated with the systems in Table 1 is the relative evaluation of their effectiveness in the context of stall warning. The Ontiveros data provides some reference for the constant tone, interrupted tone, and yoke/seat vibration, as well as the effectiveness of an interrupted tone with yoke or stick vibration. Other values need to be derived from experience, and eventually, data. Hence, it is prudent to approach these point values conservatively and update these values over time as more data becomes available.

Another challenge associated with this approach is the combination of multiple options that can form an aggregate Stall Warning score. Should the effectiveness of the systems be additive? Should credit be given only for systems with different sensory paths? Relevant research exists for these types of systems in a variety of contexts, but specific research in the context of combined effects on stall warning for many of these options has not been 
identified at this time. Again, the committee's approach is to start with conservative methods to score combinations of stall warning. In addition to limiting the value associated with adding options for stall warning, the committee is considering both a "threshold" and a "cap" for the total Stall Warning score. A "threshold" - a minimum score value - is a reaction to $\$ 23.2150(\mathrm{a})$, which states that stall warning must be present in all airplanes. This implies that some basic level of stall warning should never be compromised. A "cap" represents an upper limit on the aggregate Stall Warning score, which is consistent with the layered defense philosophy associated with Reason's model of failure. For aircraft that have additional requirements in $\$ 23.2150$ (for example, non-aerobatic single engine airplanes), the "cap" ensures that applicants do not place too much emphasis here at the expense of other areas.

\section{B. Departure Resistance}

The NPRM and NPA, and associated final rules in $\$ 23.2150(\mathrm{~b})$, indicate that all single-engine aircraft must not have a "tendency" to "inadvertently" depart controlled flight, whereas $\$ 23.2150(\mathrm{c})$ indicates that Level 1 and 2 multiengine aircraft must not have a tendency to inadvertently depart controlled flight due to a "critical loss of thrust." In both cases, the term "inadvertent" implies that applicants are not required to protect against deliberate pilot action that leads to departure, and "tendency" implies that applicants are not required to protect against grossly negligent neglect of the controls.

For single-engine airplanes, the F3180/F3180M-16 standard currently includes three alternatives for compliance with $\$ 23.2150$ (b). As discussed earlier, the first alternative is essentially the same as $\$ 23.221(\mathrm{a})(2)$, which is the "spin resistance" criteria that exists for all aircraft today. The third alternative, which only applies to Level 1 aircraft, is the same criteria that exists for CS-VLA-221(b). In both cases, these alternatives are "all or nothing," meaning that failure of any one condition or maneuver is grounds for failing the entire approach. As such, the flowchart shown previously in Figure 2 does not assign a "point" value for departure for paths that use Alternatives 1 or 3.

\section{Maneuvers}

Alternative 2, which is currently being developed by the committee, takes a graduated approach compared to the all-or-nothing criteria used for the other alternatives. It considers maneuvers with the same intent as the maneuvers used to develop the \$23.221(a)(2) spin resistance criteria, but with a "point" value assigned to the outcome of each maneuver. The total Departure Resistance score, $S_{D R}$, for Alternative 2 is the total score of all maneuvers.

Guidance for the creation of such a maneuver matrix can be found in the extensive research that led to the maneuvers defined in $\$ 23.221$ (a)(2), which was developed with NASA, the FAA, and GAMA in the 1980s and 1990s. In particular, the maneuvers used to demonstrate "spin resistance" included demonstration of:

- Lateral controllability - maneuvers designed to show that the aircraft can maintain post-stall lateral control. These include criteria to maintain wings-level flight within some tolerance, as well as demonstrate roll authority with normal control sense. These maneuvers ensure that control power is balanced such that normal use of the controls will not induce spins post-stall.

- Uncoordinated stalls ("abused" stalls) - maneuvers designed to mimic "real-world" scenarios in which a distracted pilot does not apply proper coordination of lateral and directional controls (e.g, aileron and rudder). These situations can occur power-on (such as during initial climb and go-around) or power-off (such as during a base-to-final turn). For these maneuvers, the aircraft is stalled in unaccelerated and accelerated turns while uncoordinated, and the pilot must demonstrate post-stall lateral control by returning the aircraft to wings-level flight through normal (e.g. unreversed) use of the controls.

- Sustained control abuse - maneuvers designed to evaluate the tendency of the aircraft to depart controlled flight when the controls are not coordinated for a period of time. For these maneuvers, the uncoordinated controls are held for several seconds. This enables determination of the amount of time a pilot has available between misapplication of controls and departure from controlled flight.

\section{Scoring}

For Alternative 2, scoring is commensurate with outcome. "Points" are given for each maneuver if the resistance criteria for that class of maneuver are met. The sum of "points" from each successful maneuver then creates the Departure Resistance score. Though the actual composition of the maneuver list (called the Alternative 2 Maneuver Matrix) is still being debated, many candidates are based on the spin resistance maneuvers listed above. The maximum point value for each maneuver is normalized such that successfully meeting all maneuvers would result in a Departure Resistance score of 100 . Hence, the "point" value, $X_{\text {resist }}$, of each successful maneuver is $100 / N_{M}$, where $N_{M}$ is the total number of maneuvers in the Alternative 2 Maneuver Matrix. An aircraft that meets the spin resistance criteria in $\$ 23.221$ (a)(2) would get a score of 100, whereas an aircraft that meets the spin resistance criteria for some maneuvers, but not all, would have a score of less than 100 . 
This scoring method is consistent with FAA and EASA guidance in that it does not provide any "credit" for designs that recover from spins but instead focuses on resisting the departure. One issue with this approach is that departure-resistant aircraft tend to be difficult to recover once they depart. ${ }^{18}$ Additionally, there may be merit to provide some, but not full, incentive for recoverable designs. The modern general aviation fleet contains a number of different makes and models of aircraft, most of which are designed to today's spin recovery standards. The fatal accident rate of those different types varies greatly. Though dated, Ellis' 1977 study ${ }^{14}$ shows the variation in fatal accident rate among 31 different makes and models of single-engine aircraft (many of which are still flying in today's fleet). This study indicates that the rate of fatal accidents due to "stall/mush" (which includes spins) varies from 0.12 to 3.05 per 100,000 flight hours, with an average of 0.389 . Given that these designs were all spinrecoverable, and not spin-resistant, it is reasonable to conclude that a significant reduction in fatal accident rate can still be made in spin-recoverable aircraft. It may be that these aircraft depart, but do so in a slow, deliberate fashion that gives the pilot ample time and warning to correct the departure. This is actually one of the key differences between the FAA and EASA language at the time of this writing - EASA's rule states that the aircraft must not "not have a tendency to hazardously depart controlled flight inadvertently." Hence, the committee is considering "partial credit" for maneuvers that do not meet the spin resistance criteria, but rather do meet some enhanced recovery criteria if the aircraft does depart.

To anchor the Departure Resistance score, the "threshold" and "cap" method is used, as it was with the Stall Warning score. Given that aircraft that require Departure Resistance also require Stall Warning, the limits on the Departure Resistance score are commensurate with the limits on the Stall Warning score - both are capped at a maximum of 100 points. Also, as with the Stall Warning score, the allocation of the FAA/EASA desire for "twice the safety" implies that today's average aircraft are half as departure-resistant as they need to be to meet the new rule and therefore should be able to achieve approximately $50 \%$ of this score, or 50 points. This latter stipulation helps to anchor the value assigned to the enhanced recovery criteria for maneuvers that do not meet the full departure resistance criteria.

\section{System-Based Departure Resistance}

The descriptions of the maneuvers used for Alternatives 1 or 2 have largely implied aerodynamic departure resistance or recovery, such as the wing cuffs developed under the NASA/FAA/GAMA spin resistance program. ${ }^{16}$ However, several aircraft today use active systems to prevent departure, such as "stick pushers." Several recent ELOS findings ${ }^{28,29,30,31}$ have been issued for modern aircraft using stick pushers that would affect many of the stall and departure resistance tests required by $\$ 23.2150$. The committee intends to continue to allow these systems to be used for termination of maneuvers required by Alternative 1 or 2 . The current F3180/F3180M-16 ${ }^{12}$ standard states that "maneuvers can be discontinued, and a normal recovery initiated, after a downward pitching motion of the aeroplane commences due to the activation of a stall avoidance device (for example, stick pusher activation)."

\section{Effort vs. Previous Departure-Related Guidance}

Although the NPRM and NPA stated a goal of "twice the safety at half the cost," the FAA and EASA indicated they were willing to accept additional costs of compliance in the areas of stall warning and departure characteristics, as long as those costs were offset elsewhere. Spin recovery demonstration is one area of a flight test program that typically involves substantial costs, and its elimination could provide significant cost savings. Furthermore, according to the NPRM and NPA, it provides a dubious safety benefit. However, if the cost and effort necessary to comply with Alternative 1, Alternative 2, or Alternative 3 is prohibitive, the safety benefit may not be realized.

Given that Alternatives 1 and 3 are essentially the same as departure resistance criteria used in previous rules and these alternatives were rarely employed, it stands to reason that they are likely not cost-effective in the current market. Approached correctly, this should not be the case with Alternative 2. The maneuvers currently envisioned for the Alternative 2 maneuver matrix will result in approximately 70-100 combinations for typical aircraft. This is in contrast to several hundred maneuvers used in a typical spin recovery maneuver matrix. ${ }^{32}$ Although the number of maneuvers for Alterative 2 may be similar to Alternative 1, the fact that Alternative 2 uses a continuous score metric, rather than a single pass/fail based on completion of all maneuvers, should enable a number of "good" but not "perfect" designs to move forward. As an example, the Columbia 300, which completed most of the maneuvers successfully for the \$23.221(a)(2) spin resistance criteria (now Alternative 1), required an ELOS finding because it could not pass all of the maneuvers at all required conditions. ${ }^{33}$ Under Alternative 2, the Columbia 300 would have a high Departure Resistance score, slightly less than 100. Hence, with the addition of a small amount of SafetyEnhancing Features (see next section), the Columbia 300 would not require an ELOS finding.

A "hard" threshold at a Departure Resistance score of 50 may also be considered a cost burden. However, the committee is considering language that would require (rather than simply allow) a particular class of Safety- 
Enhancing Features (namely, a Descent Arrest System) that meets minimum performance criteria for aircraft with a Departure Resistance Score less than 50. This would be similar to the ELOS criteria offered for the Cirrus SR20, which required enhanced stall handling characteristics and a ballistic recovery parachute system. ${ }^{34}$

\section{Multiengine Aircraft}

The other major change associated with departure resistance involves $\$ 23.2150(\mathrm{c})$, which is related to the departure of the aircraft following a critical loss of thrust. The committee is currently investigating performancebased and systems-based protection features that enhance the departure resistance of multiengine aircraft following a critical loss of thrust. To date, the committee has largely focused on the other areas of $\$ 23.2150$ and intends to develop options to deal with multiengine critical loss of thrust in the near future.

\section{Safety-Enhancing Features}

The Stall Warning score and, if required, Departure Resistance score, enable applicants to achieve less than $100 \%$ compliance with $\$ 23.2150(\mathrm{a})$ and $\$ 23.2150(\mathrm{~b})$, respectively. However, if the applicant chooses a path that scores less than $100 \%$ in either of these areas, they must include Safety-Enhancing Features to increase their Departure Aversion Score to the required level. Safety-Enhancing Features is envisioned by the committee as an "a la carte" menu of options that applicants may choose to bring up their total Departure Aversion score. Currently, three categories of Safety-Enhancing Features are considered:

- Enhanced Indication Systems - systems intended to provide additional information regarding the lowspeed airplane control and performance state, beyond the requirements of the Flight Instrumentation described in ASTM Standard F3061 ${ }^{35}$ and the Markings and Placards described in ASTM Standard $\mathrm{F} 3117^{36}$.

- Enhanced Envelope Awareness Systems - systems intended to provide control feedback when the flight crew provides control inputs that place the aircraft in realms that have reduced margin over loss-ofcontrol. Stall barrier devices (such as stick pushers) and envelope-limiting control systems are not considered here; such devices are instead used for compliance with maneuvers associated with demonstration of stall and post-stall behavior. In essence, an Enhanced Envelope Awareness System is designed to allow the flight crew to override the system without deactivating it; true "full authority" systems are designed to override the flight crew control inputs. ${ }^{\dagger}$

- Descent Arrest Systems - systems intended to slow the descent of an aircraft that has departed controlled flight and place the aircraft in an attitude and at an appropriate velocity such that the resulting impact with the ground does not violate the maximum impact loads specified in ASTM Standard F3083. ${ }^{37}$

\section{Enhanced Indication Systems}

The Enhanced Indication Systems (EIS) concept relates to the NPRM preamble material noted earlier indicating the FAA was interested in "allowing new approaches to improve pilot awareness of stall margins... as simple as angle of attack or energy awareness presentations..." as a means to improve low-speed awareness. Current ideas under consideration for EIS include:

- $\quad$ angle-of-attack indication, with additional credit for trend information,

- angle-of-attack driven pitch limit indication displayed with attitude indication, with additional credit for trend information,

- dynamic low-speed airspeed markings, such as angle-of-attack driven V-speeds on an airspeed tape,

- $\quad$ airspeed trend information/marker displayed with airspeed,

- $\quad$ altitude trend information displayed with altitude,

- $\quad$ flight path marker displayed with attitude indication, and

- loss of control alert issued when loss of control is likely within trend window.

\section{Enhanced Envelope Awareness Systems}

The Enhanced Envelope Awareness Systems (EEAS) concept relates to the NPRM preamble material noted earlier indicating the FAA was interested in "... envelope protection systems that add a forward force to the pilot's controls as the airplane speed and attitude approach stall." As noted earlier, EEAS are not meant to be "full-

\footnotetext{
† There are cases where the flight crew has overpowered "full authority" systems (e.g., Colgan Air flight 3047 ${ }^{38}$ ), but such systems are designed to standards that suppose the system will override flight crew inputs.
} 
authority" systems, but rather systems that provide control feedback that can be overridden by the flight crew as loss of control margins are reduced. This is explained as the "H-Metaphor" in NASA-sponsored research.$^{39} \mathrm{Here}$, the HMetaphor is likened to a rider on a horse - the horse normally goes where the rider commands it, but as threats are encountered by the horse (e.g., the horse is directed to ride through a dense patch of thorns), the horse resists the rider's commands. The rider may be able to control the horse towards the threat, but with increased control effort. As the threat to the horse increases, so does the resistance of the horse to rider commands.

Similarly, automatic control systems can provide feedback to the user. Yaw dampers have existed for the rudder control for many different aircraft for decades. Many modern aircraft are equipped with two-axis autopilots, and the market has seen recent introduction of products that use autopilots as a mechanism to artificially increase stability as low-speed control margin is reduced. For example, Garmin ${ }^{\circledR}$ announced in 2015 that it was bringing "Electronic Stability and Protection" to systems that utilize the Garmin ${ }^{\circledR}$ autopilot. ${ }^{40}$ More recently, manufacturers have investigated digital engine controls that may result in autothrottle systems coming to the light aircraft market (such devices are prevalent in today's large aircraft market).

The current working hypothesis for generating "points" for EEAS is to apply a point value to the control axis associated with the EEAS systems (pitch, roll, yaw, thrust). Additionally, standards are in development that describe the amount of feedback (force) and activation criteria for each of these control axes.

\section{Descent Arrest Systems}

Although Descent Arrest Systems (DAS) are not explicitly mentioned in the NPRM or NPA, they have become more popular in the market in the form of whole airframe parachutes. The most notable example in the certified aircraft market is the Cirrus series of aircraft. In the case of the Cirrus SR20, the airframe parachute was a contributing factor in the ELOS decision ${ }^{34}$ for relief from \$23.221.

As in consideration now, Descent Arrest Systems are largely focused on development of standards for aircraft equipped with airframe parachutes, drawing from the ELOS argument for the Cirrus SR20. Namely, the ELOS was granted partially on the basis of the altitude loss associated with parachute deployment and aircraft deceleration being less than or equal to the altitude loss associated with typical light aircraft spin recoveries. Notably, the altitude loss for these systems (and for spin recovery) typically exceeds the altitude of aircraft in a traffic pattern, which is where a number of LOC accidents occur. Hence, minimal safety credit is given for DAS that have large altitude loss. However, the committee is considering a "sliding scale" to encourage development of DAS concepts that result in less altitude loss during deployment to full steady-state operation. Overall, just like the other Safety-Enhancing Features, the DAS cannot be the only mechanism in place to mitigate LOC accidents.

\section{Scoring}

As with the Stall Warning score and Departure Resistance score, the Safety Enhancing Features score is capped to ensure that applicants are required to install multiple layers of defenses, in line with the Reason model of protection described earlier. Currently, one proposed idea is to place a "cap" of approximately 40 points each on the three categories of Safety-Enhancing Features (EIS, EEAS, and DAS). This means that, theoretically, an applicant could make up 120 points with "perfect" systems in all three categories.

Additionally, the individual point values for each "a la carte" system are much lower than the baseline thresholds associated with Stall Warning and Departure Resistance, largely because the efficacy of such systems has not been rigorously established as a mitigation for loss of control. As history with these systems evolves, the individual point values assigned to various systems may increase.

Finally, in an effort to retain the value of Non-Required Safety-Enhancing Equipment (NORSEE) currently allowed by the FAA, ${ }^{41}$ the same type of equipment noted as Safety-Enhancing Equipment may continue to be installed via NORSEE if it is not used to generate credit for the Departure Aversion Score. The NORSEE policy allows for such equipment to be installed if it can be shown to "do no harm" to existing equipment. This is a lower bar than would be allowable for the same equipment if it were to be used for credit for the Departure Aversion score, since it would make the equipment "required" for compliance with $\$ 23.2150$.

\section{Notional Implementation}

To illustrate how the Departure Aversion approach might be used, a few notional aircraft are brought through the process. These notional aircraft are based on the four aircraft tested as part of NASA's spin resistance program. These aircraft were representative of types of aircraft produced in the United States at the time, but were individually modified for use as test aircraft by NASA. These modifications included accommodations for test equipment, and later changes to incorporate spin-resistance technology concepts. Initially, however, these aircraft were tested with no spin-resistance technologies incorporated, in particular to establish the spin tendency of the 
aircraft with pro-spin controls. The four experimental aircraft are described in Table 2. Note that the aircraft designations, while similar to aircraft manufactured at that time, are all appended with " $\mathrm{X}$ " to denote that these were experimental modifications of aircraft. The number of passengers is listed instead of number of seats, since the number of passengers is used to define the "Level" that would be assigned in today's $\$ 23.2005$ (all aircraft have an additional seat for the minimum flight crew - in these cases, one pilot). Spin entry frequency of the original aircraft prior to spin-resistance modification is shown as "Orig. Spin Frequency," and spin entry frequency after the application of the spin reduction technology is shown as "Mod. Spin Frequency." The Departure Aversion points requirement is based on Figure 2, assuming all aircraft use Alternative 2 to meet $\$ 23.2150(\mathrm{~b})$.

Table 2. Experimental Aircraft Used in NASA Spin Resistance Testing (adapted from Ref. 16)

\begin{tabular}{|c|c|c|c|c|}
\hline Designation & AA-1X & C-23X & PA-28RX & C- $172 \mathrm{X}$ \\
\hline Orig. Spin Frequency & $96 \%$ & $98 \%$ & $83 \%$ & $59 \%$ \\
\hline Mod. Spin Frequency & $0 \%$ & $5 \%$ & $5 \%$ & $0 \%$ \\
\hline No. of Passengers & 1 & 3 & 3 & 3 \\
\hline$\$ 23.2005$ Level & 1 & 2 & 2 & 2 \\
\hline$S_{D A}$ "Points" Req'd & 150 & 200 & 200 & 200 \\
\hline
\end{tabular}

To determine the Departure Aversion score of these aircraft in an unmodified state, it is necessary to assign point values to various features associated with Stall Warning, as well as to maneuvers associated with the Alternative 2 Maneuver Matrix. Notional point values for different Stall Warning systems, based on the options from Table 1, are given below in Table 3. Note that this scoring system assumes that any system beyond the first system gets only half credit, and, as mentioned earlier, the total available score is capped at 100. Also, for now, this analysis will assume that only one system of a given sensory path can be installed (e.g., no credit for constant tone + synthetic voice).

Table 3. Notional Stall Warning Score for Various Stall Warning Systems

\begin{tabular}{lll} 
Sensory Path & Description & Points \\
\hline Aural & Constant tone & 50 \\
Aural & Interrupted tone & 60 \\
Aural & Synthetic voice & 70 \\
Tactile & Seat vibration & 50 \\
Tactile & Yoke or stick vibration & 90 \\
Visual & Visual indication independent of pilot focus & 25 \\
Visual & Visual indication in primary field of view & 10 \\
(All) & Credit for each system beyond first system installed & $50 \%$ \\
(All) & Maximum score (no matter how many installed) & 100 \\
\hline
\end{tabular}

The types of maneuvers discussed in Section IV.B of this paper can help determine the number of maneuvers in the Alternative 2 Maneuver Matrix. Assumptions are that all aircraft have three flap positions (clean, intermediate, and full), aircraft with retractable gear (PA-28RX) are tested with gear down in all but the flaps clean configuration, and the configurations are tested power-on and power-off at the most adverse CG position and weight. The uncoordinated maneuvers are conducted in left and right turns, with the ball inside and outside of the turn. The sustained control abuse maneuvers include both neutral aileron and aileron opposite to the rudder. With these assumptions, the total number of maneuvers for these aircraft is $N_{M}=90$. This results in $X_{\text {resist }}=100 / 90=1.11$ per maneuver. If the aircraft cannot pass the resistance criteria, but can recover from the ensuing departure, it receives $1 / 3$ the credit, resulting in a "point" value for enhanced recovery $X_{\text {recov }}=1.11 / 3=0.37$ per maneuver. Note that these are very similar to the maneuvers required by $\$ 23.221$ (a)(2), though the degree of sustained control above may be tailored such that these are not full spin-entry inputs, but rather a modified forward slip during stall for the opposite ailerons. A summary of the notional maneuver categories is given in Table 4. 
Table 4. Notional Summary of Alternative 2 Maneuver Matrix

\begin{tabular}{|ll}
\hline Maneuver Type & Number \\
\hline Power-off, coordinated lateral controllability & 3 \\
\hline Power-on, coordinated lateral controllability & 3 \\
\hline Power-off, wings-level uncoordinated stalls & 6 \\
\hline Power-on, wings-level uncoordinated stalls & 6 \\
\hline Power-off, turning uncoordinated stalls & 12 \\
\hline Power-on, turning uncoordinated stalls & 12 \\
\hline Power-off, accelerated turning uncoordinated stalls & 12 \\
\hline Power-on, accelerated turning uncoordinated stalls & 12 \\
\hline Power-off, sustained control abuse, neutral aileron & 6 \\
\hline Power-on, sustained control abuse, neutral aileron & 6 \\
\hline Power-off, sustained control abuse, opposite aileron & 6 \\
\hline Power-on, sustained control abuse, opposite aileron & 6 \\
\hline Total & 90 \\
\hline
\end{tabular}

All of the unmodified aircraft are assumed to have a traditional single-tone stall warning horn, for a stall warning score of $S_{W}=50$ per Table 3. Though it is difficult to make an assumption regarding the disposition of maneuvers for each unmodified aircraft, a number of assumptions are made for the sake of an initial evaluation. First, the unmodified aircraft are assumed to be able to meet the full resistance criteria for the six coordinated lateral controllability maneuvers, given that these are slight enhancements to the controllability demonstrations seen in the variant of 23.201 that was in force when these aircraft were certified. The unmodified aircraft are otherwise assumed to resist the remaining 84 maneuvers according to the complement of spin frequency rate (e.g, $\left.1-f_{s}\right)$. A final assumption is made that the maneuvers that result in a departure all result in a recovery to the enhanced spin recovery criteria, which may be optimistic. Hence, the Departure Resistance Score will be: $S_{D R}=[6+(1-$ $\left.\left.f_{s}\right)\right] X_{\text {resist }}+84 f_{s} X_{\text {recov }}$, where $f_{s}$ is the Spin Frequency from Table 2. Under this notional system, the aircraft described in Table 2 will achieve the scores shown in Table 5.

Table 5. Notional Scores of Aircraft Used for NASA Spin Resistance Program

\begin{tabular}{lllll} 
Aircraft & AA-1X & C-23X & PA-28RX & C-172X \\
\hline $\boldsymbol{S}_{\boldsymbol{W}}$ & 50 & 50 & 50 & 50 \\
\hline $\boldsymbol{S}_{\boldsymbol{D} R}$, original & 38.7 & 38.8 & 49.0 & 59.1 \\
$\boldsymbol{S}_{\boldsymbol{D} R}$, with modifications & 100.0 & 92.6 & 92.6 & 100.0 \\
$\boldsymbol{S}_{\boldsymbol{D} A}$, original & $88.7 / 150$ req'd & $88.8 / 200$ req'd & $99.0 / 200$ req'd & $109.1 / 200$ req'd \\
$\boldsymbol{S}_{\boldsymbol{D A}}$, with modifications & $150.0 / 150$ req'd & $142.6 / 200$ req'd & $142.6 / 200$ req'd & $150 / 200$ req'd
\end{tabular}

Per these estimates, none of the unmodified aircraft would meet the Departure Aversion criteria, and the modified AA-1X tested by NASA with the spin resistance modifications (leading edge cuffs) would just barely meet the criteria (note that this is a Level 1 aircraft, so it has a lower score requirement). Also, the average Stall Warning score for all aircraft is 50, and the average Departure Resistance score is 46.4. Both of these values are close to the desire to have today's status quo be around 50 points for both categories.

The unmodified aircraft have a Departure Aversion score deficit ranging from 61.3 to 111.2 , and the spinresistant aircraft have a deficit ranging from 0.0 to 80.6 . In all cases, up to 50 additional points could be added by installing better stall warning systems. If the horn in all aircraft were augmented with a stick shaker, then, per the rules in Table 3, each aircraft would receive a maximum score for Stall Warning (90 points for the tactile yoke or stick vibration, plus $50 \times 1 / 2=25$ points for the aural constant tone, capped at 100 per the notional rules). Eliminating the horn and installing a synthetic voice system along with some sort of cockpit-mounted visual indication would yield 75 points $(70+10 \times 1 / 2)$. The specific combination is up to the applicant and likely guided by cost and ease of installation. Assuming that most applicants select a path that brings $S_{S W}$ to 100 , the Departure Aversion score deficit would range from 11.3 to 61.2 for the aircraft without the NASA spin resistance features, and 0 to 7.4 points for the aircraft with these features. This deficit is well within the upper limits of the envisioned point values for the Safety-Enhancing Features (capped at 40 for EIS, 40 for EAS, and 40 for DAS, noting that DAS would likely be substantially lower with today's technology). For example, if each applicant installed EIS systems that included dynamic airspeed markings at a notional 10 points and an angle-of-attack indicator at a notional 5

14

American Institute of Aeronautics and Astronautics 
points, they would have an EIS score of 15 . An additional notional 10 points per control axis of an EEAS would bring 20 points for a two-axis autopilot that used an H-Metaphor approach for control feedback. This brings the combined Safety Enhancing Features score to 35 points, which would be nearly enough for several of the unmodified aircraft with better Stall Warning.

These notional results do not indicate that applicants would be forced to add the NASA spin resistance technology to their aircraft, at least not to the same extremes as applied to the example aircraft. For example, the Columbia 300, referenced earlier, would have a very high Departure Resistance Score, though it would not reach a full 100 points in this area. With increased stall warning, and a modest increase in Enhanced Indication, such an aircraft would likely reach the 200-point threshold required for non-aerobatic, single-engine Level 2 aircraft.

\section{Conclusions}

Inflight loss of control is a vexing problem that has remained a consistent accident category for light aircraft for decades. Recent changes to the certification rules for light aircraft, namely 14 CFR Part 23 in the United States and CS-23 in Europe, have targeted this category of accidents by requiring enhanced stall warning and post-stall characteristics. These rule changes also recognize that the requirement for demonstration of spin recovery in certification programs does not provide a benefit commensurate with the associated cost. In most cases, departure from controlled flight occurs at altitudes that preclude proper recovery action. The FAA and EASA guidance shifts the focus from recovery towards (1) providing the pilot with greater warning for an impending LOC situation, and (2) providing controllability for more time after a stall to allow a pilot to take proper action prior to a full departure.

At the same time, the revised certification rules have moved away from prescriptive requirements and towards performance-based standards. In so doing, the FAA and EASA are enabling a faster adoption of new technologies, along with a more flexible approach for establishing means of compliance. This allows consensus organizations, such as ASTM International Committee F44 on General Aviation, to develop means of compliance that meet the performance-based intent of the certification rules in a way that is responsive and flexible to their members (who represent regulators, users, and producers).

As part of this effort, a new method is being developed to respond to the new FAA and EASA rules regarding departure from controlled flight. This approach, dubbed Departure Aversion, uses a point-based scale that allows for multiple combinations of options, while retaining the core desires of the regulators to increase requirements in the area of stall warning and handling characteristics in departure-prone situations. Departure Aversion uses a layered approach that assumes that faults will continue to occur, and that the system is able to catch these faults prior to becoming accidents through multiple, different defenses. This is similar to the design of high-reliability systems.

The Departure Aversion approach focuses on the key areas of Stall Warning and Departure Resistance by leveraging data from FAA and NASA research programs on stalls, spins, and spin resistance. However, it does not specify a pure pass/fail based maneuver system, but rather it allows for "corners of the envelope" to remain uncovered if the overall, holistic aversion to departure from controlled flight is increased. By placing upper and lower limits on points for individual contributing factors, Departure Aversion forces a layered defense.

Furthermore, the Departure Aversion approach seizes on recent technology developments in Safety-Enhancing Features. Previously, such equipment would only be installed in experimental category aircraft, or through NORSEE provisions. Now, it is possible to get "certification credit" for $\$ 23.2150$ through the Departure Aversion approach for these types of systems. They are not required, but if necessary, they can be used by an applicant.

Though the committee is still balloting the details of the Departure Aversion approach, a notional, but plausible, set of "point" values was devised by the author and compared to aircraft tested as part of the NASA/FAA/GAMA spin resistance programs in the 1980s. The result of this analysis showed that the aircraft tested as part of that exercise were indeed deficient in terms of meeting the new standard, but they each had plausible paths to meet the new standard. This shows that the safety goals are likely achievable using the Departure Aversion approach, without a prohibitive cost or effort increment. Furthermore, by allowing multiple different paths to compliance, applicants can select the most cost-effective approach, rather than following one or a few prescribed mechanisms.

There is much work that still needs to be done. Multiple different mechanisms are being debated amongst the consensus standards committees today regarding compliance with FAA and EASA rules for stall warning and departure characteristics, and usable standards will be necessary by the time the new rules become active in August 2017. More effort will be needed to help craft the standards that address these rules, and they will be far from perfect. As manufacturers develop solutions, preferred routes and potential "loopholes" will likely be discovered. These must be addressed systematically, with data from relevant research programs and applications. The various systems described in this paper are excellent candidates for future investigation in the context of LOC mitigation, and this represents a ripe area of research for improved aviation safety. 


\section{Acknowledgments}

NASA's presence on this committee is funded through the Aeronautics Systems Analysis Branch and Systems Analysis \& Concepts Directorate of NASA's Langley Research Center. The author is grateful for NASA's support of this effort to improve aviation safety. The author wishes to thank Paul Stough for his correspondence regarding NASA's general aviation spin testing program through the 1990s. Mr. Stough's experience and insights were exceptionally valuable during the creation of alternatives described in this paper. The author also wishes to thank Lowell Foster of the FAA for providing valuable insight regarding the recent FAA rulemaking efforts related to the revision of 14 CFR Part 23. Finally, the extensive experience of the ASTM International Committee F44 on General Aviation, especially those on the F44.20 Flight Characteristics subcommittee, have been instrumental in the development of this approach.

\section{References}

1. "Revision of Airworthiness Standards for Normal, Utility, Acrobatic, and Commuter Category Airplanes," Federal Aviation Administration Notice of Proposed Rulemaking, Federal Register, 81:49 pp. 13451-13528, 14 March 2016.

2. "Reorganisation of CS-23," European Aviation Safety Agency Notice of Proposed Amendment 2016-05, 23 June 2016.

3. "Committee F44 on General Aviation Aircraft," ASTM International, https://www.astm.org/COMMITTEE/F44.htm, accessed 13 October 2016.

4. " $25^{\text {th }}$ Joseph T. Nall Report: General Aviation Accidents in 2013," Aircraft Owner's and Pilot's Association Air Safety Institute, Frederick, MD, 2016.

5. “Approach and Landing \& Departure and En-Route," General Aviation Joint Steering Committee Loss of Control Working Groups, 29 October 2014.

6. "Revision of Airworthiness Standards for Normal, Utility, Acrobatic, and Commuter Category Airplanes," Federal Aviation Administration Final Rule, Federal Register, 81:251 pp. 96572-96701, 30 December 2016.

7. "Certification Specifications for Normal-Category Aeroplanes," CS-23, Amendment 5, European Aviation Safety Agency, 29 March 2017.

8. "Light-Sport Aircraft Airworthiness Certification: Special Considerations for Special Airworthiness Certificates," Federal Aviation Administration, Airworthiness Certification Branch, AIR-230, 8 July 2013.

9. "Certification Specifications and Acceptable Means of Compliance for Light Sport Aeroplanes," CS-LSA, Amendment 1, European Aviation Safety Agency, 29 July 2013.

10. “Committee F37 on Light Sport Aircraft, ASTM International, https://www.astm.org/COMMITTEE/F37.htm, accessed 13 October 2016.

11. "Recommendations for increasing the safety of small general aviation airplanes certificated to 14 CFR part 23," Report from the 14 CFR Part 23 Reorganization Aviation Rulemaking Committee, Federal Aviation Administration, 5 June 2013.

12. "Standard Specification for Low-Speed Flight Characteristics of Aeroplanes," F3180/F3180M-16, ASTM International, March 2016.

13. "Special Study: General Aviation Stall/Spin Accidents, 1967-1969," National Transportation Safety Board, Report NTSBAAS-72-8, 13 September 1972.

14. D. R. Ellis, "A Study of Lightplane Stall Avoidance and Suppression," U.S. Department of Transportation, Federal Aviation Administration, Report FAA-RD-77-25, February 1977.

15. R. J. Ontiveros, "Experimentation and Evaluation of Improved Stall Warning Equipment," U.S. Department of Transportation, Federal Aviation Administration, Report NA-69-35 (DS-69-15), December 1969.

16. H. P. Stough III, D. J. DiCarlo, "Spin Resistance Development for Small Airplanes - A Retrospective," SAE 2000-01-1691, GA Technology 2000 Conference, Wichita, KS, 9-11 May 2000.

17. Code of Federal Regulations, Title 14 (Aeronautics and Space), Chapter I (Federal Aviation Administration, Department of Transportation), Subchapter C (Aircraft), Part 23, (Airworthiness Standards: Normal, Utility, Acrobatic, and Commuter Category Airplanes), Amendment 62, U.S. Government Publishing Office, 31 January 2012.

18. C. E. Arnold, "Spin Resistant Airplane Certification Issues," SAE 87-1849, 1988.

19. "Experiments Result in Safer, Spin-Resistant Aircraft," NASA Spinoff 2013, National Aeronautics and Space Administration, Office of the Chief Technologist, 2013.

20. "Certification Specifications for Very Light Aeroplanes," CS-VLA, Amendment 1, European Aviation Safety Agency, 5 March 2009.

21. "FAA Regulations," Federal Aviation Administration, http://www.faa.gov/regulations_policies/faa_regulations/, accessed 13 October 2016.

22. Type Certificate Data Sheet A00003SE, Revision 27, Department of Transportation, Federal Aviation Administration, 22 June 2016.

23. Type Certificate Data Sheet A00009CH, Revision 20, Department of Transportation, Federal Aviation Administration, 27 June 2016.

24. J. Reason, "Human error: models and management," British Medical Journal, 320:768-770, 2000.

25. "Human Error - Systemic Model," Human Factors Awareness Course, Federal Aviation Administration, http://www.hf.faa.gov/webtraining/teamperform/teamcrm009.htm, accessed 8 May 2017. 
26. N. Borer, I. R. Claypool, R. G. Odegard, W. D. Clark, K. Somervill, N. Suzuki, "Model-Driven Development of Reliable Avionics Architectures for Lunar Surface Systems," 2010 IEEE Aerospace Conference, Big Sky, Montana, 6-13 March 2010.

27. R. Ball, The Fundamentals of Aircraft Combat Survivability Analysis and Design, Second Edition, American Institute of Aeronautics and Astronautics, New York, 2003.

28. L. Foster, "Equivalent Level of Safety, Pilatus PC-12; Finding No. ACE-94-8," U.S. Department of Transportation, Federal Aviation Administration, June 1994.

29. J. Morfitt, "Equivalent Level of Safety (ELOS) Finding for Epic Aircraft, LLC., Model E1000 Airplane, Use of Stick Pusher/Shaker System in lieu of compliance with Spin Recovery Requirements, FAA Project \# TC11773SE-A," ELOS Memo \# TC11773SE-A-F-1, U.S. Department of Transportation, Federal Aviation Administration, 8 June 2016.

30. W. Rouse, "Equivalent Level of Safety (ELOS) Finding for Kestrel Aircraft Company, Model K-350 Airplane, FAA Project TC7859CH-A," ELOS Memo \# TC7859CH-A-F-1, U.S. Department of Transportation, Federal Aviation Administration, 8 June 2016.

31. W. Rouse, "Equivalent Level of Safety (ELOS) Finding for Cirrus Design Corporation, Model SF50 Jet, Spin Requirements, FAA Project \#: TC6444CH-A,” ELOS Memo \# TC6444CH-A-F-2, Federal Aviation Administration, 12 July 2016.

32. "Flight Test Guide for Certification of Part 23 Airplanes," Advisory Circular, AC 23-8C, U.S. Department of Transportation, Federal Aviation Administration, November 2011.

33. J. Morfitt, "Project No. TC1616SE-A - Pacific Aviation Composites (PACUSA) Lancair LC40-550FG - Requesting Review of and Concurrence with Equivalent Level of Safety (ELOS), FAR's 23.201, 23.203, and 23.221, Stalls and Spins, ACE-98-1," U.S. Department of Transportation, Federal Aviation Administration, 3 September 1998.

34. L. Foster, "Equivalent Level of Safety to $\$ 23.221$; Cirrus Designs SR-20; Finding No. ACE-96-5," U.S. Department of Transportation, Federal Aviation Administration, 10 June 1998.

35. "Standard Specification for Systems and Equipment in Small Aircraft," F3061/F3061M-16b, ASTM International, 2016.

36. "Standard Specification for Crew Interface in Aircraft," F3117-15, ASTM International, 2015.

37. "Standard Specification for Emergency Conditions, Occupant Safety and Accommodations," F3083/F3083M-16, ASTM International, 2016.

38. "Aircraft Accident Report: Loss of Control on Approach, Colgan Air, Inc., Operating as Continental Connection Flight 3407, Bombardier DHC-8-400, N200WQ, Clarence Center, New York, February 12, 2009,” NTSB/AAR-10/01, PB2010910401, Notation 8090A, National Transportation Safety Board, Washington, D.C., February 2010.

39. F. O. Flemisch, C. A. Adams, S. R. Conway, K. H. Goodrich, M. T. Palmer, P. C. Schutte, "The H-Metaphor as a Guideline for Vehicle Automation and Interaction," NASA/TM-2003-212672, National Aeronautics and Space Administration, Langley Research Center, Hampton, Virginia, December 2003.

40. "Garmin ${ }^{\circledR}$ Brings Safety Enhancing Electronic Stability and Protection To G3X ${ }^{\mathrm{TM}}$ And G3X Touch Systems That Utilize Garmin Autopilot," http://newsroom.garmin.com/press-release/featured-releases/garmin-brings-safety-enhancing-electronicstability-and-protection-g, accessed 10 May 2017.

41. "Approval of Non-Required Safety Enhancing Equipment (NORSEE)," Policy No. PS-AIR-31.8-1602, U.S. Department of Transportation, Federal Aviation Administration, 31 March 2016. 